CrossMark $\quad$ Open Medicine Journal

RESEARCH ARTICLE

\title{
The Use of Robotic Assisted Surgery; the Current and Future Challenges
}

\author{
Reza Mafi $^{1, *}$, Pouya Mafi ${ }^{2}$ and Marco Malahias ${ }^{3}$ \\ ${ }^{I}$ Nuffield Department of Orthopaedics, Rheumatology and Musculoskeletal Sciences, University of Oxford, England, \\ $U K$ \\ ${ }^{2}$ Barts and The London NHS Trust, Whipps Cross University Hospital, London, UK \\ ${ }^{3}$ Department of Plastic Surgery, Heart of England NHS Foundation Trust, UK
}

Received: June 28, 2015

Revised: September 17, 2016

Accepted: September 17, 2016

\begin{abstract}
:
Background:

Living with robots has always been regarded as a science fiction theme, however due to rapid advances in technology it is becoming more of a reality. The use of robots in surgery dates back to more than 25 years, and has previously been of great assistance to humans in the fields of Aeronautics and Armed forces. An evolutionary step was made after collaboration between the National Aeronautics and Space Administration (NASA), and the Stanford Research Institute in the field of robotic-assisted surgery. Thereafter, more surgical specialties incorporated this technology in surgical procedures. The objective of this article is to review different applications, challenges, and the future of robotic surgery.
\end{abstract}

\section{Methods:}

We have used a systematic approach to look at the most relevant published articles regarding robotic-assisted surgery. This review has taken 26 articles into consideration that have met the inclusion criteria of using of robotic- assisted technology in surgical procedures.

\section{Conclusion:}

Robotic surgery is being used in numerous surgical fields such as pediatrics, urology, cardiovascular surgery, gynecology, otolaryngology, general surgery and orthopedics. It has resulted in a reduction in length of stay, post-operative complication and scarring. However, for achieving optimal outcomes, further development in improving the sensory feedback and reducing the lag time during the transmission of long-range telesurgery is required.

Keywords: Robotic Assisted Surgery, Robotic Surgery, Telesurgery.

\section{BACKGROUND}

In 1985 robots were first used to assist surgeons during a neurosurgical operation for taking a CT guided biopsy [1]. It did not take long before more advanced forms of robots were developed for urological procedures. These could be used to guide transurethral resection of the prostate through three-dimensional images created preoperatively [2]. Soon thereafter an upgrade called ROBODOC facilitated orthopedic operations such as total hip replacement [3]. ROBODOC was designed to maneuver the femur with greater precision in hip replacement surgeries.

As a result of collaboration between Scientists from the National Aeronautics and Space Administration (NASA) and the Stanford Research Institute, important steps were made towards the communication between the operator and

* Address correspondence to this author at the Nuffield Department of Orthopaedics, Rheumatology and Musculoskeletal Sciences, University of Oxford, England, UK; Tel: + 44(0)1482875875; Fax: +44(0)1482875875; E-mail: reza.mafi@ndorms.ox.ac.uk 
the robotic instruments [4]. Together, they were able to improve the telemanipulation by the surgeon. This achievement further advanced the minimally invasive laparoscopic surgery and led to development of telesurgery [5, 6]. This concept was initially funded by the Pentagon's Defense Advanced Research Projects Agency (DARPA), with the goal of allowing a surgeon to treat a wounded soldier on the battlefield, from a remote safe haven with the surgeon's hands controlling robotic arms [7 - 9].

Robots can now be classified under their characterization as automated arms, mobile devices, mills, or telerobotic devices. In addition to this, they can be active, semiactive, or passive. Active devices are totally programmable and carry out tasks independently. Semiactive devices and passive robotic devices function by translating movements from the operator's hands into powered or unpowered movements of the robot end-effector arms [10].

\section{THE DA VINCI SYSTEM}

At present, the "da Vinci" is the most commonly used robotic system. Under the control of the surgeon the robot can be used to cut, suture, grasp and dissect [11]. Furthermore, when compared to traditional laparoscopic techniques there is significant improvement in dexterity, depth perception, camera stability, and surgeon ergonomics [6].

This system consists of four robotic arms of which three are instrumental and one is the endoscope. Trocars are attached at the end of each arm, which are inserted into patient through small incisions. The surgeon can manipulate these arms by cabled 'endowrist' instruments, which mimic the freedom of human hand and wrist motion, only by sitting at a console away from the operation bed. The wristed robotic instruments, along with the articulations of the robotic arms, allow the surgeon seven degrees of freedom: the external robotic arms provide three degrees of freedom (insertion, pitch, and yaw) and the Endowrist ${ }^{\circledR}$ mechanism provides four additional degrees of freedom (pitch, yaw rotation and grip) [12]. The console's monitor provides a three-dimensional view of the surgical field and by using pedals the focus can be adjusted. This way the surgeon does not need to take his hands off the console to manually adjust the focus [13]. These advantages have resulted in significant improvement in performance and safety of intracorporeal suturing, which in turn make the surgical robot a powerful tool especially when a high degree of precision in a tight space is required [14]. Table $\mathbf{1}$ demonstrates the current applications of robotic-surgery.

\section{ADVANTAGES AND CHALLENGES}

Since the birth of the robotic-assisted surgery, there has been major improvement in the quality of the operations and outcomes when compared with laparotomy [13]. Among the most important are reductions in post-operative pain, recovery time and complications including blood loss, scaring, transfusion and wound infection. Furthermore, it reduces the length of stay and a quicker return to normal activities and work, which in turn can be of financial benefit to the hospital and economy. (1) According to recent cost analyses, efficiencies gained through robotic surgery may translate into significant operating room cost reductions. Therefore, the widely held belief that robotic surgery is 'too expensive' may not be true after all [13].

In a traditional laparoscopic operation, the surgeon is required to stand in an ergonomically contorted fashion following the operation on a two dimensional monitor, while holding two instruments at the same time and communicating camera maneuvers to a colleague over several hours. Consequently, these factors contribute to an increased level of fatigue and frustration for the surgeon, whereas the robotic surgeon is seated, has full control over a three-dimensional view and better precision of movement. It has been reported that the learning curve for the surgeon is much shorter compared to conventional laparoscopic surgery [15]. This could be explained as they need to work with long instruments through a fixed entry point, while watching a screen with reduced tactile feedback, leading to diminished fine motor control, tremor amplification and difficult hand-eye coordination [12].

All the benefits mentioned above come with a cost. These include the high cost of the robotic platform, disposable instruments and annual service contracts. Other limitations to robotic-assisted laparoscopic surgery include the lack of haptics, or tactile feedback [15], the fixed positioning of the operating table, the longer operative time compared to open surgery and the limited data on the outcome of operations [1].

One of the other challenges that this mode of surgery is facing is transmission delay over long distances. The maximum effective range seems to be approximately 30 miles by wireless communication and 200 miles via a cable connection [16]. At distances greater than this, the lag time between the surgeon's movements and the movement of the robotic arms can be quite disorienting [17]. 
Table 1. Current Applications demonstrates the use of robotic assisted surgery in various surgical fields.

\begin{tabular}{|c|c|c|c|}
\hline Surgical field & Nature of operation & Author & Outcome compared to traditional method \\
\hline \multirow{2}{*}{ Thoracic } & $\begin{array}{l}\text { Robotic assisted minimally invasive surgery for atrial } \\
\text { septal defect correction }\end{array}$ & Poffo et al. [18] & $\mathrm{N} / \mathrm{A}$ \\
\hline & Robotic-assisted coronary artery bypass surgery. & Halkos et al. [19] & $\begin{array}{l}\text { - Reduced bleeding } \\
\text { - Effective alternative to traditional method }\end{array}$ \\
\hline Gynecology & Robotic-assisted laparoscopic hysterectomy & Holloway et al. [13] & $\begin{array}{l}\text { - Fewer wound complications } \\
\text { - Less post-op pain }\end{array}$ \\
\hline \multirow{3}{*}{ General surgery } & Computer-assisted robotic antireflux surgery & Gould et al. [17] & $\begin{array}{l}\text { - Safe and effective } \\
\text { - Little advantage over standard laparoscopic } \\
\text { approach }\end{array}$ \\
\hline & Robotic-assisted colorectal surgery & Kim et al. [20] & $\begin{array}{l}\text { - Lower intra-and post operative complications } \\
\text { - Shorter LOS } \\
\text { - Less blood loss } \\
\text { - Comparable oncological outcome } \\
\text { - Longer operation time (LOT) }\end{array}$ \\
\hline & $\begin{array}{l}\text { Ablative and reconstructive robotic-assisted laparoscopic } \\
\text { renal surgery. }\end{array}$ & Murphy et al. [21] & $\begin{array}{l}\text { - Mechanical failure did occur } \\
\text { - Safe method } \\
\text { - Reducing LOS }\end{array}$ \\
\hline Orthopedics & Robotic Surgery in Total Hip Arthroplasty & Nobuhiki et al. [22] & $\begin{array}{l}\text { - Better stem alignment } \\
\text { - Less variance in limb-length inequality }\end{array}$ \\
\hline Otolaryngology & Robotic-assisted salvage surgery for oropharyngeal cancer. & Dean et al. [23] & $\begin{array}{l}\text { - Acceptable procedure for resection of both } \\
\text { primary and recurrent oropharyngeal tumors. } \\
\text { - Fewer gastrostomy tube dependent post } \\
\text { operatively } \\
\text { - Reduced LOS }\end{array}$ \\
\hline Pediatrics & Abdominal and thoracic robotic-assisted surgery & Meehan et al. [24] & $\begin{array}{l}\text { - Safe and effective in complex neonatal cases } \\
\text { - Ideal of hepatobiliary and thoracic cases. }\end{array}$ \\
\hline Urology & Robotic-assisted radical prostatectomy (RARP) & Watts et al. [25] & $\begin{array}{l}\text { - Reduced LOS } \\
\text { - Reduced transurethral catheter duration } \\
\text { - Marginal reduction in operation time }\end{array}$ \\
\hline
\end{tabular}

\section{FUTURE DEVELOPMENTS}

The future of the robotic-assisted surgery is looking very bright. Currently robotic engineers are working on devices with more streamlined platforms, smaller instrumentation, and remote telementoring. In addition, there is a great deal of research and funding spent on improving the sensory feedback on the telerobotic devices for creating better outcomes [26].

It is very likely that in the foreseeable future the cost of robotic surgery reduces with the inevitable advent of competitors in the market. Consequently, this factor would lead to a great cost saving to both patients and hospitals, as well as allowing more patients to benefit from this type of minimally invasive surgery.

\section{CONCLUSION}

Robotic surgery is being used in numerous surgical fields such as pediatrics, urology, cardiovascular surgery, gynecology, otolaryngology, general surgery and orthopedics. It has resulted in a reduction in length of stay, postoperative complication and scarring. However, for achieving optimal outcomes, further development in improving the sensory feedback and reducing the lag time during the transmission of long-range telesurgery is required.

\section{CONFLICT OF INTEREST}

The authors confirm that this article content has no conflict of interest.

\section{ACKNOWLEDGEMENTS}

Declared none. 


\section{REFERENCES}

[1] Leddy L, Lendvay T, Satava R. Robotic Surgery applications and cost effectiveness. Open Access Surgery 2010; 3: 99-107.

[2] Kwoh YS, Hou J, Jonckheere EA, Hayati S. A robot with improved absolute positioning accuracy for CT guided stereotactic brain surgery. IEEE Trans Biomed Eng 1988; 35(2): 153-60. [http://dx.doi.org/10.1109/10.1354] [PMID: 3280462]

[3] Davies BL, Hibberd RD, Coptcoat MJ, Wickham JE. A surgeon robot prostatectomya laboratory evaluation. J Med Eng Technol 1989; 13(6): 273-7. [http://dx.doi.org/10.3109/03091908909016201] [PMID: 2614807]

[4] Bauer AB, Lahmer A. Clinical experience with a medical robotic system for total hip replacement. In: In: Nolte LP, Granz R, Eds. Computer Assisted Orthopedic Surgery Bern: Hogeye \& Huber, 1999. pp. 128-133

[5] Walters L, Eley S. Robotic-assisted surgery and the need for standardized pathways and clinical guidelines. AORN J 2011; 93(4): 455-63. [http://dx.doi.org/10.1016/j.aorn.2010.05.032] [PMID: 21459183]

[6] Lanfranco AR, Castellanos AE, Desai JP, Meyers WC. Robotic surgery: a current perspective. Ann Surg 2004; 239(1): 14-21. [http://dx.doi.org/10.1097/01.sla.0000103020.19595.7d] [PMID: 14685095]

[7] Gourin CG, Terris DJ. History of robotic surgery. In: Faust RA, Ed Robotic in Surgery History, Currecnt and Future Applications, Newyork: Nova Science. 2006

[8] Gourin CG, Terris DJ. Surgical robotics in otolaryngology: expanding the technology envelope. Curr Opin Otolaryngol Head Neck Surg 2004; 12(3): 204-8. [http://dx.doi.org/10.1097/01.moo.0000122309.13359.af] [PMID: 15167030]

[9] Ballantyne GH. Robotic surgery, telerobotic surgery, telepresence, and telementoring. Review of early clinical results. Surg Endosc 2002; 16(10): 1389-402. [http://dx.doi.org/10.1007/s00464-001-8283-7] [PMID: 12140630]

[10] Hockstein NG, Gourin CG, Faust RA, Terris DJ. A history of robots: from science fiction to surgical robotics. J Robot Surg 2007; 1(2): 113-8. [http://dx.doi.org/10.1007/s11701-007-0021-2] [PMID: 25484946]

[11] Meadows M. Robots lend a helping hand to surgeons. FDA Consum 2002; 36(3): 10-5. [PMID: 12085803]

[12] Chen CC, Falcone T. Robotic gynecologic surgery: past, present, and future. Clin Obstet Gynecol 2009; 52(3): 335-43. [http://dx.doi.org/10.1097/GRF.0b013e3181b08adf] [PMID: 19661749]

[13] Holloway RW, Ahmad S. Robotic-assisted surgery in the management of endometrial cancer. J Obstet Gynaecol Res 2012; 38(1): 1-8. [http://dx.doi.org/10.1111/j.1447-0756.2011.01744.x] [PMID: 22136216]

[14] Stefanidis D, Wang F, Korndorffer JR Jr, Dunne JB, Scott DJ. Robotic assistance improves intracorporeal suturing performance and safety in the operating room while decreasing operator workload. Surg Endosc 2010; 24(2): 377-82. [http://dx.doi.org/10.1007/s00464-009-0578-0] [PMID: 19536599]

[15] Visco AG, Advincula AP. Robotic gynecologic surgery. Obstet Gynecol 2008; 112(6): 1369-84 [http://dx.doi.org/10.1097/AOG.0b013e31818f3c17] [PMID: 19037049]

[16] Ditlea S. Available from: http://wwwtechnologyreviewcom/featuredstory/400816/robosurgeons/ 2000

[17] Gould JC, Melvin WS. Computer-assisted robotic antireflux surgery. Surg Laparosc Endosc Percutan Tech 2002; 12(1): 26-9. [http://dx.doi.org/10.1097/00129689-200202000-00004] [PMID: 12008758]

[18] Poffo R, Celullare AL, Pope RB, Toschi AP. Robotic assisted minimally invasive surgery for atrial septal defect correction. Rev Bras Cir Cardiovasc 2012; 27(3): 488-90. [http://dx.doi.org/10.5935/1678-9741.20120083] [PMID: 23288196]

[19] Halkos ME, Liberman HA, Devireddy C, et al. Early clinical and angiographic outcomes after robotic-assisted coronary artery bypass surgery. J Thorac Cardiovasc Surg 2014; 147(1): 179-85. [http://dx.doi.org/10.1016/j.jtcvs.2013.09.010] [PMID: 24172691]

[20] Kim CW, Kim CH, Baik SH. Outcomes of Robotic-Assisted Colorectal Surgery Compared with Laparoscopic and Open Surgery: a Systematic Review. J Gastrointest Surg 2014; 18(4): 816-30. [http://dx.doi.org/10.1007/s11605-014-2469-5]

[21] Murphy D, Challacombe B, Olsburgh J, et al. Ablative and reconstructive robotic-assisted laparoscopic renal surgery. Int J Clin Pract 2008; 62(11): 1703-8. [http://dx.doi.org/10.1111/j.1742-1241.2007.01563.x] [PMID: 18284446]

[22] Sugano N. Computer-assisted orthopaedic surgery and robotic surgery in total hip arthroplasty. Clin Orthop Surg 2013; 5(1): 1-9. [http://dx.doi.org/10.4055/cios.2013.5.1.1] [PMID: 23467021]

[23] Tan GY, Goel RK, Kaouk JH, Tewari AK. Technological advances in robotic-assisted laparoscopic surgery. Urol Clin North Am 2009; 36(2): 237-249, ix. [ix.]. [http://dx.doi.org/10.1016/j.ucl.2009.02.010] [PMID: 19406324] 
[24] Meehan JJ, Sandler A. Pediatric robotic surgery: A single-institutional review of the first 100 consecutive cases. Surg Endosc 2008; 22(1): $177-82$.

[http://dx.doi.org/10.1007/s00464-007-9418-2] [PMID: 17522913]

[25] Watts R, Botti M, Beale E, Crowe H, Costello AJ. Patient outcomes in the acute recovery phase following robotic-assisted prostate surgery: a prospective study. Int J Nurs Stud 2009; 46(4): 442-9.

[http://dx.doi.org/10.1016/j.ijnurstu.2007.07.010] [PMID: 17825304]

[26] Madhani AJ, Salisbury JK. The black falcon: a teleoperated surgical instrument for minimally invasive surgery. IEEE/RSJ International Conference on Intelligent Robots and Systems, 1998.

[http://dx.doi.org/10.1109/IROS.1998.727320]

(C) Mafi et al.; Licensee Bentham Open

This is an open access article licensed under the terms of the Creative Commons Attribution-Non-Commercial 4.0 International Public License (CC BY-NC 4.0) (https://creativecommons.org/licenses/by-nc/4.0/legalcode), which permits unrestricted, non-commercial use, distribution and reproduction in any medium, provided the work is properly cited. 